\title{
Bundling in exchange markets with indivisible goods
}

Citation for published version (APA):

Dimitrov, D., Haake, C. J., \& Klaus, B. E. (2005). Bundling in exchange markets with indivisible goods. METEOR, Maastricht University School of Business and Economics. METEOR Research Memorandum No. 028 https://doi.org/10.26481/umamet.2005028

Document status and date:

Published: 01/01/2005

DOI:

10.26481/umamet.2005028

Document Version:

Publisher's PDF, also known as Version of record

\section{Please check the document version of this publication:}

- A submitted manuscript is the version of the article upon submission and before peer-review. There can be important differences between the submitted version and the official published version of record.

People interested in the research are advised to contact the author for the final version of the publication, or visit the DOI to the publisher's website.

- The final author version and the galley proof are versions of the publication after peer review.

- The final published version features the final layout of the paper including the volume, issue and page numbers.

Link to publication

\footnotetext{
General rights rights.

- You may freely distribute the URL identifying the publication in the public portal. please follow below link for the End User Agreement:

www.umlib.nl/taverne-license

Take down policy

If you believe that this document breaches copyright please contact us at:

repository@maastrichtuniversity.nl

providing details and we will investigate your claim.
}

Copyright and moral rights for the publications made accessible in the public portal are retained by the authors and/or other copyright owners and it is a condition of accessing publications that users recognise and abide by the legal requirements associated with these

- Users may download and print one copy of any publication from the public portal for the purpose of private study or research.

- You may not further distribute the material or use it for any profit-making activity or commercial gain

If the publication is distributed under the terms of Article $25 \mathrm{fa}$ of the Dutch Copyright Act, indicated by the "Taverne" license above, 


\title{
Bundling in exchange markets with indivisible goods*
}

\author{
Dinko Dimitrov $^{\dagger} \quad$ Claus-Jochen Haake ${ }^{\dagger} \quad$ Bettina Klaus ${ }^{\ddagger}$
}

March 2006

\begin{abstract}
We study efficient and individually rational exchange rules for markets with heterogeneous indivisible goods that exclude the possibility that an agent benefits by bundling goods in her endowment. Even if agents' preferences are additive, no such rule exists.
\end{abstract}

JEL Classification: C71, D63, D71.

Keywords: exchange markets; indivisible goods; bundling-proofness.

\section{Introduction}

We consider exchange markets with heterogeneous indivisible objects where each agent is endowed with a set of objects and monetary transfers are not possible. Examples are the exchange of equipment and tasks among workers or departments of a firm (Papái, 2005; Atlamaz and Klaus, 2005). Our model of exchange includes housing markets (Shapley and Scarf, 1974: each agent owns exactly one object, which can be traded) and multiple-type housing markets (Moulin, 1995; Konishi et al., 2001: each agent's endowment consists of one object of each type and agents are allowed to trade different types of indivisible objects). An exchange rule assigns to each trader a set of objects. We are interested in exchange rules satisfying appealing properties such as efficiency, individual rationality (no agent is worse off after trading) and robustness to manipulations. A strong nonmanipulation requirement, strategy-proofness (no agent benefits from misrepresenting her preferences), is known to be incompatible with efficiency and individual rationality (Sönmez, 1999; Konishi et al., 2001).

In exchange markets agents may also have an incentive to manipulate the outcome using their endowments, for example, by hiding, destroying, or transferring part of them. The study of hiding-proofness and destruction-proofness in the context of classical exchange economies goes back to Postlewaite (1979), while transfer-proof rules were studied by Sertel and Özkal-Sanver (2002) for two-sided matching with endowments. Atlamaz and Klaus (2005) analyzed these three manipulation possibilities for exchange markets with indivisible goods. In particular, they show that efficient and individually rational

\footnotetext{
${ }^{*}$ We thank William Thomson for his comments. Financial support from the Alexander von Humboldt Foundation (D. Dimitrov) and from the FiF-Project "Fairness und Anreize" at Bielefeld University (C.-J. Haake) is gratefully acknowledged.

${ }^{\dagger}$ Institute of Mathematical Economics, Bielefeld University, P.O. Box 100131, 33501 Bielefeld, Germany; e-mails: d.dimitrov@wiwi.uni-bielefeld.de, CHaake@wiwi.uni-bielefeld.de.

${ }^{\ddagger}$ Corresponding author: Department of Economics, Maastricht University, P.O. Box 616, 6200 MD Maastricht, The Netherlands; e-mail: B.Klaus@algec.unimaas.nl; tel.: +31-433884605; fax: +31-433884878.
} 
rules are generally not immune to manipulations via endowments, with some exceptions for two-agent exchange markets.

We are also interested in exchange rules that prevent the possibility of manipulation via endowments, but focus on bundling-proofness: no agent benefits from bundling goods in her endowment. To fix ideas, we assume that bundling and decomposition of bundles are costless and the only effect of bundling is that bundled objects have to be traded together. To keep the model simple we assume that agents' endowments consist of disjoint sets of objects and interpret the objects in each set as being bundled. Now, an exchange rule assigns to each agent a set of objects such that trade restrictions given by the agents' endowment distribution are respected. Since bundling-proofness can be interpreted as a much weaker requirement than strategy-proofness (Remark 1), there is hope to restore compatibility of "non-manipulation" with efficiency and individual rationality. Unfortunately, even for additive preferences, no bundling-proof, efficient, and individually rational exchange rule exists (Theorem 1).

\section{Exchange markets with indivisible objects}

Let $K$ be a finite set of heterogeneous objects with $|K| \geq 2$ and $N=\{1, \ldots, n\}$ a finite set of agents $(n \geq 2)$. We denote by $2^{K}$ the set of all subsets of $K$. Each agent $i \in N$ has an endowment $B_{i}$ that consists of disjoint sets of objects $B_{i}^{k}$, i.e., $B_{i}=\left(B_{i}^{1}, \ldots, B_{i}^{l(i)}\right)$ is such that (a) for all $k \in\{1, \ldots, l(i)\}, B_{i}^{k} \in 2^{K}$, and (b) for all $k, k^{\prime} \in\{1, \ldots, l(i)\}$ $\left(k \neq k^{\prime}\right), B_{i}^{k} \cap B_{i}^{k^{\prime}}=\emptyset$. We say that objects in $B_{i}^{k}$ are bundled. By $E_{i}=\bigcup_{k=1}^{l(i)} B_{i}^{k} \in 2^{K}$ we denote the set of objects agent $i$ owns. The set of all endowments for agent $i$ is denoted by $\mathcal{B}_{i}$. For example, $B_{i}=\left(B_{i}^{1}, B_{i}^{2}, B_{i}^{3}\right)=(\{a, b\},\{c\},\{d, e, f\})$ means that agent $i$ owns objects $a, b, c, d, e, f$ and $E_{i}=\{a, b, c, d, e, f\}$. Furthermore, objects $a$ and $b$ are bundled, and objects $d, e$, and $f$ are bundled as well. An endowment distribution $B=\left(B_{1}, \ldots, B_{n}\right)$ satisfies the following two conditions: (i) for all $i \in N, B_{i} \in \mathcal{B}_{i}$ and (ii) for all $i, j \in N$ $(i \neq j), E_{i} \cap E_{j}=\emptyset$. We denote the set of all endowment distributions by $\mathcal{B}$.

Each agent $i \in N$ has complete and transitive preferences $R_{i}$ over $2^{K}$ with $P_{i}$ being the associated strict preference relation. We let $\mathcal{R}_{i}$ denote the set of all preferences for agent $i, R=\left(R_{i}\right)_{i \in N}$ a preference profile, and $\mathcal{R}=\mathcal{R}_{1} \times \ldots \times \mathcal{R}_{n}$ the set of all preference profiles.

Given a preference profile $R \in \mathcal{R}$ and an endowment distribution $B \in \mathcal{B}$, we denote an (exchange) market by $(R, B)$. Since in the remainder of the article we assume that the preference profile remains fixed while endowment distributions may vary, we simply denote a market by its endowment distribution $B \in \mathcal{B}$. An allocation for a market $B \in \mathcal{B}$ is a list $\left(S_{1}, \ldots, S_{n}\right)$ such that

1. each agent $i \in N$ receives some subset $S_{i} \subseteq \bigcup_{i=1}^{n} E_{i}$,

2. no two agents receive the same object, i.e., for all $i, j \in N(i \neq j), S_{i} \cap S_{j}=\emptyset$, and

3. objects that are bundled in an agent's endowment are assigned jointly, i.e., for all $i \in N, B_{i}=\left(B_{i}^{1}, \ldots, B_{i}^{l(i)}\right)$, and all $k \in\{1, \ldots, l(i)\}$, either $B_{i}^{k} \subseteq S_{j}$ for some $j \in N$ or $B_{i}^{k} \cap \bigcup_{i \in N} S_{i}=\emptyset$. 
The first two conditions are standard, while the third condition is specific to our setting and simply requires that an allocation respects all trade restrictions that bundling in the endowments creates. Note that we allow for free disposal, that is, $\bigcup_{i=1}^{n} S_{i} \varsubsetneqq \bigcup_{i=1}^{n} E_{i}$ is possible.

Finally, notice that on the one hand agents are endowed with bundles of objects while on the other hand preferences are not defined over bundles but over subsets. The reason for this way of modeling is that we assume that bundles impose trade restrictions but the fact that objects are bundled does not change these objects physically.

\section{Efficiency, individual rationality, and bundling-proofness}

An (exchange) rule is a function $\varphi$ that associates with each market $B \in \mathcal{B}$ an allocation $\varphi(B)=\left(S_{i}\right)_{i \in N}$. Given $i \in N$, we call $\varphi_{i}(B)$ the allotment of agent $i$ at $\varphi(B)$.

We assume that a rule only chooses (Pareto) efficient allocations: for all $B \in \mathcal{B}$ there is no allocation $\left(S_{i}\right)_{i \in N}$ such that for all $i \in N, S_{i} R_{i} \varphi_{i}(B)$, with strict preference holding for some $j \in N$.

To express voluntary participation or individual rationality, we assume that agents find their allotments at least as good as their endowments: for all $B \in \mathcal{B}$ and all $i \in N$, $\varphi_{i}(B) R_{i} E_{i}$.

The main property we focus on in this paper is bundling-proofness. We assume that any agent can costlessly increase the degree of bundling in her endowment. By increasing the degree of bundling we mean that an agent can merge some of the subsets in her endowment to larger bundles, e.g., agent $i$ with $B_{i}=\left(B_{i}^{1}, B_{i}^{2}, B_{i}^{3}\right)=(\{a, b\},\{c\},\{d, e, f\})$ could bundle $\{c\}$ with $\{d, e, f\}$ and announce $\hat{B}_{i}=(\{a, b\},\{c, d, e, f\})$. This bundling implies that now objects $c, d, e$, and $f$ have to be assigned to the same agent after trade.

More generally, for any agent $i$ with endowment $B_{i}$ a bundled endowment $\hat{B}_{i}=$ $\left(\hat{B}_{i}^{1}, \ldots, \hat{B}_{i}^{\hat{l}(i)}\right)[\hat{l}(i) \leq l(i)]$ is a partition of $E_{i}$ such that for all $k \in\{1, \ldots, l(i)\}$ there exists $\hat{k} \in\{1, \ldots, \hat{l}(i)\}$ such that $B_{i}^{k} \subseteq \hat{B}_{i}^{\hat{k}}$, which means that $\hat{B}_{i}$ is a coarser partition than $B_{i}$. Given $B \in \mathcal{B},\left(\hat{B}_{i}, B_{-i}\right)$ denotes the endowment distribution obtained from $B$ by replacing $B_{i}$ by $\hat{B}_{i}$.

We require that if agent $i$ bundles her endowment, then she finds her allotment without bundling at least as good as her allotment with bundling, given all other agents do not manipulate their endowments. A rule $\varphi$ is bundling-proof if for all $B \in \mathcal{B}$, all $i \in N$, and all bundled endowments $\hat{B}_{i}, \varphi_{i}(B) R_{i} \varphi_{i}\left(\hat{B}_{i}, B_{-i}\right)$.

Remark 1. As mentioned in the Introduction, it is well-known that efficiency, individual rationality, and strategy-proofness are not compatible in our model (Sönmez, 1999).

Assume that a rule is efficient and individually rational. Then, the power an agent has by misrepresenting her preferences is to reduce the set of efficient and individually rational allocations, possibly to her benefit. By bundling objects in her endowment, an agent also can reduce the set of efficient and individually rational allocations. Note that through preferences complementarities between any set of objects can be expressed, which in combination with efficiency and individual rationality may lead to trade restrictions that also concern other agents' objects. By bundling fewer trade restrictions can be imposed and therefore we can interpret bundling-proofness as a much weaker requirement than strategy-proofness. 
We consider now the additive preference domain: agent $i$ 's preferences are additive if there is a function $u_{i}: K \rightarrow \mathbb{R}\left(u_{i}(\emptyset)=0\right)$ such that for all $T, T^{\prime} \in 2^{K}, T R_{i} T^{\prime}$ if and only if $\sum_{k \in T} u_{i}(k) \geq \sum_{k \in T^{\prime}} u_{i}(k)$. We show that on this domain no rule is efficient, individually rational, and bundling-proof. Clearly, this result also holds on any preference domain that contains the domain of additive preferences.

Theorem 1. For markets with additive preferences, no rule is efficient, individually rational, and bundling-proof.

Proof. Let $N=\{1,2\}, B=\left(B_{1}, B_{2}\right)$ such that $B_{1}=(\{a\},\{b\},\{c\}), B_{2}=(\{d\},\{e\})$. Preference profile $\left(R_{1}, R_{2}\right)$ has the following utility representation:

$$
\begin{array}{l|l}
\hline u_{1}(a)=1.5, & u_{2}(a)=2.9 \\
u_{1}(b)=1.3, & u_{2}(b)=1.8 \\
u_{1}(c)=1.1, & u_{2}(c)=1.5 \\
u_{1}(d)=3, & u_{2}(d)=3 \\
u_{1}(e)=0.01, & u_{2}(e)=0.5
\end{array}
$$

Since all objects have positive values, by individual rationality no agent will give up an object without receiving at least one other object from the other agent. By individual rationality, agent 1 is willing to swap either $\{a\},\{b\},\{c\},\{a, b\},\{a, c\}$, or $\{b, c\}$ for $\{d\}$ or $\{d, e\}$ (no individually rational swap for agent 1 involves only object $e$ ). By individual rationality, agent 2 is willing to swap $\{d\}$ for $\{a, b, c\},\{a, b\},\{a, c\}$, or $\{b, c\}$ or swap $\{d, e\}$ for $\{a, b, c\},\{a, b\}$, or $\{a, c\}$. Hence, the only individually rational allocations are $A^{1}=$ $(\{a, b, c\},\{d, e\}), A^{2}=(\{c, d\},\{a, b, e\}), A^{3}=(\{b, d\},\{a, c, e\}), A^{4}=(\{a, d\},\{b, c, e\})$, $A^{5}=(\{c, d, e\},\{a, b\})$, and $A^{6}=(\{b, d, e\},\{a, c\})$. Allocation $A^{1}$ is not efficient (it is Pareto dominated by $A^{2}$ ). Among the remaining allocations, allocation $A^{4}$ gives the highest utility to agent 1.

Now assume that agent 1 bundles objects $b$ and $c$, i.e., consider $\left(\hat{B}_{1}, B_{2}\right)$ where $\hat{B}_{1}=$ $(\{a\},\{b, c\})$. Then the only efficient and individually rational allocation for $\left(\hat{B}_{1}, B_{2}\right)$ is $\left.A^{4}=(\{a, d\}),\{b, c, e\}\right)$. Thus, by bundling-proofness, $\varphi(B)=A^{4}$.

Next, assume that agent 2 bundles objects $d$ and $e$, i.e., consider $\left(B_{1}, \hat{B}_{2}\right)$ where $\hat{B}_{2}=$ $(\{d, e\})$. Then the only efficient and individually rational allocations for $\left(B_{1}, \hat{B}_{2}\right)$ are $A^{5}=$ $(\{c, d, e\}),\{a, b\})$ and $A^{6}=(\{b, d, e\},\{a, c\})$. If $\varphi_{2}\left(B_{1}, \hat{B}_{2}\right)=A^{5}$, then, in contradiction to bundling-proofness, $\{a, b\}=\varphi_{2}\left(B_{1}, \hat{B}_{2}\right) P_{2} \varphi_{2}\left(B_{1}, B_{2}\right)=\{b, c, e\}$. If $\varphi_{2}\left(B_{1}, \hat{B}_{2}\right)=A^{6}$, then, again in contradiction to bundling-proofness, $\{a, c\}=\varphi_{2}\left(B_{1}, \hat{B}_{2}\right) P_{2} \varphi_{2}\left(B_{1}, B_{2}\right)=$ $\{b, c, e\}$.

Hence, for $n=2$, efficiency, individual rationality, and bundling-proofness are incompatible. For $n>2$, we simply add agents who prefer their endowments to any other set of objects. Since only agents 1 and 2 trade in this case, the incompatibility persists for $n>2$.

Note that the example used in the proof of Theorem 1 is not only minimal with respect to the number of agents, but also with respect to the number of objects used. 


\section{Conclusion}

The setup presented in this paper differs from the standard exchange model with heterogeneous indivisible goods (Papái, 2005; Atlamaz and Klaus, 2005) in that it allows for more structure in agents' endowments that implicitly expresses trade restrictions. Our impossibility result in this framework is in accordance with the non-existence of efficient, individually rational, and hiding-proof rules (Atlamaz and Klaus, 2005) and, more generally, with the non-existence of efficient, individually rational, and strategy-proof rules (Sönmez, 1999).

Since we assume that bundling is costless and objects do not change by bundling, agents can also decompose or regroup bundles in their endowments (Dimitrov and Haake, 2005). Note that when decomposing endowment, more feasible allocations are created. Hence, as demonstrated in the next example, decomposition may in fact be efficiency enhancing. Therefore, efficiency and "decomposition-proofness" are not compatible.

Example 1. Let $N=\{1,2\}$ and $B=\left(B_{1}, B_{2}\right)$ such that $B_{1}=(\{a, b\})$ and $B_{2}=(\emptyset)$. Preferences are additive such that $u_{1}(a)=1, u_{1}(b)=-1, u_{2}(a)=-1$, and $u_{2}(b)=1$. The only feasible allocations are $(\{a, b\}, \emptyset)$ and $(\emptyset,\{a, b\})$ with final utilities $(0,0)$.

Next assume that agent 1 decomposes $B_{1}$ into $B_{1}^{\prime}=(\{a\},\{b\})$. Thus, for $B^{\prime}=$ $\left(B_{1}^{\prime}, B_{2}\right)$ the additional feasible allocations are $(\{a\},\{b\})$ and $(\{b\},\{a\})$. The associated final utilities are $(1,1)$ and $(-1,-1)$. Hence, the only feasible and efficient allocation is $(\{a\},\{b\})$ with final utilities $(1,1)$.

\section{References}

[1] Atlamaz, M. and B. Klaus, 2005, Manipulation via endowments in exchange markets with indivisible goods, Social Choice and Welfare, forthcoming.

[2] Dimitrov, D. and C.-J. Haake, 2005, Regrouping of endowments in exchange markets with indivisible goods, IMW Working Paper 367, Bielefeld University.

[3] Konishi, H., T. Quint, and J. Wako, 2001, On the Shapley-Scarf economy: the case of multiple types of indivisible goods, Journal of Mathematical Economics 35, 1-15.

[4] Moulin, H., 1995, Cooperative microeconomics (Princeton University Press, Princeton).

[5] Papái, S., 2005, Exchange in a general market with indivisible goods, Journal of Economic Theory, in press.

[6] Postlewaite, A., 1979, Manipulation via endowments, Review of Economic Studies 46, 255-262.

[7] Sönmez, T., 1999, Strategy-proofness and essentially single-valued cores, Econometrica 67, 677-689.

[8] Sertel, M. and Ï. Özkal-Sanver, 2002, Manipulability of the men- (women-) optimal matching rule via endowments, Mathematical Social Sciences 44, 65-83.

[9] Shapley, L. and H. Scarf, 1974, On cores and indivisibility, Journal of Mathematical Economics 1, 23-37. 